\title{
Effect of adjuncts on sensory properties and consumer liking of Scamorza cheese
}

\author{
A. Braghieri, ${ }^{*}$ N. Piazzolla, ${ }^{*}$ A. Romaniello, ${ }^{*}$ F. Paladino,† A. Ricciardi, ${ }^{*}$ and F. Napolitano*1 \\ *Scuola di Scienze Agrarie, Forestali, Alimentari ed Ambientali, Università degli Studi della Basilicata, 85100 Potenza, Italy \\ †Consiglio per la Ricerca e la Sperimentazione in Agricoltura, Unità di ricerca per la Zootecnia Estensiva, 85054 Muro Lucano (PZ), Italy
}

\begin{abstract}
The present study aimed to evaluate the effect of a peptidolytic adjunct (Lactococcus lactis, Lactobacillus helveticus, and Lactobacillus paracasei), as a tool to accelerate ripening, on sensory properties and acceptability of Scamorza cheese obtained using 2 types of milk (Friesian and Friesian + Jersey) and Streptococcus thermophilus as primary starter. A 10-member panel was trained using a specific frame of references and used a specific vocabulary to assess cheese sensory properties through quantitative descriptive analysis (QDA), whereas 87 consumers were used to evaluate product acceptability. Analysis of variance showed that milk type did not markedly alter cheese sensory properties. Conversely, panelists perceived higher intensities of butter, saltiness, and sweetness flavors in cheese without adjunct culture (ST), whereas the addition of the adjunct culture $(\mathrm{ST}+\mathrm{A})$ induced higher and sourness flavors, oiliness and grainy textures, and lower adhesiveness, moisture, springiness, and tenderness. Principal component analysis showed positive relationships between $\mathrm{pH}$ and tenderness, sweetness and saltiness and a negative correlation between $\mathrm{pH}$ and grainy, oiliness, color and structure uniformity, sourness, and milk. Most of the differences observed in QDA and most of the relationships observed in the principal component analysis were linked to the higher microbial activity induced by the adjunct culture. Independently of milk and starter types, consumers perceived Scamorza cheese as characterized by a good eating quality (mean liking scores were all above the neutral point of the hedonic scale). Although ST cheeses showed higher values for overall liking, 2 homogeneous groups of consumers were identified using partial least squares regression analysis. One group preferred ST cheeses with higher levels of tenderness, adhesiveness, springiness, and moisture in terms of texture, butter in terms of flavor, and sweetness in terms of taste, whereas a second group
\end{abstract}

Received July 1, 2014.

Accepted September 29, 2014.

${ }^{1}$ Corresponding author: fabio.napolitano@unibas.it preferred ST + A products characterized by specific attributes of texture (cohesiveness and oiliness), flavor (milk), taste (sourness), and appearance (structure and color uniformity). We conclude that further studies for the development of short-ripened products based on the use of adjunct cultures should be conducted to promote product differentiation and meet the sensory requirements of particular segments of consumers.

Key words: Scamorza, pasta filata cheese, adjunct, sensory analysis, consumer segmentation

\section{INTRODUCTION}

Scamorza is one of several short-ripened, pasta filata cheeses produced in Italy. This cheese category was once produced using milk from local breeds characterized by low milk yields and high DM contents. In the last decades, these breeds have gradually been replaced by higher-producing breeds, such as the Italian Friesian, although the lower DM content of their milk may limit cheese yield. Consequently, many farmers currently include other breeds, such as Jersey cows, in the herd to improve this aspect. As the breed can affect milk chemical composition, effects can also be observed on cheese texture and volatile composition, potentially affecting the sensory properties of the product (Coulon et al., 2004). A further element affecting pasta filata cheese sensory properties is the increasing accumulation of microbial metabolism products during ripening, when significant proteolysis can occur because of bacterial activity (Gobbetti et al., 2002; Piraino et al., 2005). The short ripening time used in Scamorza cheese manufacture may result in a less flavored, flat product. Adjunct cultures are often used to allow ripening in a shorter period because they affect the volatile composition (Ayad et al., 2000; Lee et al., 2007; Van Hoorde et al., 2010) and possibly also their sensory profile. However, if the sensory properties of cheese do not fulfill consumer expectations, the product will fail in the market (Braghieri et al., 2014). Several studies have assessed the sensory characteristics of pasta filata cheeses. Specific quantitative vocabularies have been produced for hard (Esposito et al., 2014), semi-hard (Carpino et 
al., 2004), and fresh pasta filata cheese (Pagliarini et al., 1997), including ewe milk Scamorza cheese (Albenzio et al., 2013). However, different manufacturing processes differently affect the chemical and volatile composition of cheese and consequently its sensory profile. In addition, as in any other animal product, cheese shows several sources of variability, such as individual animals, feeding, farming conditions, breed, and process characteristics, which necessitates the development of a specific training program to standardize sensory assessments among panelists, based on a quantitative frame of references (Braghieri et al., 2012). As to market success, the hedonic acceptability of cheese can be assessed through consumer studies based on the use of relatively large panels that are able to indicate average preferences values. However, more focused studies are needed to understand which attributes are the most important in affecting overall acceptability, whereas a partial least squares (PLS) regression approach is needed to gather information about consumer clustering over different products, as different groups of consumers may prefer products with different sensory properties (Braghieri et al., 2009). This approach has been applied to different dairy products to study quantitative relationships between sensory attributes and chemical variables (Virgili et al. 1994; Frister et al. 2000), whereas much less is known about the relationship between sensory properties and consumer liking in pasta filata cheese.

Therefore, the main aim of the present study was the evaluation of the effect of an adjunct culture, as a tool to accelerate ripening, on sensory properties and acceptability of Scamorza cheese obtained using 2 types of milk (Italian Friesian and Friesian + Jersey). We also aimed to develop a specific vocabulary and a frame of reference for Scamorza cheese quantitative descriptive analysis (QDA), investigate the relationship between Scamorza cheese sensory properties and consumer liking, and identify the driver of consumer liking in terms of specific sensory attributes.

\section{MATERIALS AND METHODS}

\section{Products}

Cheese-making trials were carried out according to a randomized block design using four 40-L vats on each cheese-making day, with 3 replicates. Two types of milk were used: 100\% from Italian Friesian cattle (F) and mixed milk containing $90 \%$ from Italian Friesian cattle $+10 \%$ Jersey $(\mathbf{M})$. Both types were obtained from local dairy farms and 2 different starters were added to each: (1) Streptococcus thermophilus (ST; Lyofast ST051, Sacco Srl, Cadorago, Italy), and (2) Strep. thermophilus (Lyofast ST051) plus an adjunct culture $(\mathbf{S T}+\mathbf{A})$. The adjunct culture was prepared by cultivating Lactococcus lactis ssp. lactis $\mathrm{C} 4 \mathrm{~F} 11$ and Lactobacillus helveticus L206 in reconstituted (11\% vol/vol) skim milk (Oxoid, Basingstoke, UK) for $16 \mathrm{~h}$ at 30 and $37^{\circ} \mathrm{C}$, respectively, and Lactobacillus paracasei ssp. paracasei C3D7 in reconstituted $(11 \% \mathrm{vol} / \mathrm{vol})$ skim milk containing $0.5 \%$ glucose and $0.25 \%$ yeast extract (Oxoid) for $16 \mathrm{~h}$ at $30^{\circ} \mathrm{C}$ (Guidone et al., 2015). The 4 treatments were designated FST, FST+A, MST, and MST+A.

The cheese-making technique for Scamorza, a semihard pasta filata cheese, was used. The milk was heat treated at $65^{\circ} \mathrm{C}$ for $10 \mathrm{~min}$ and cooled at $38^{\circ} \mathrm{C}$. Liquid veal rennet (1:18,000, Caglificio Clerici Spa, Cadorago, Italy) was added $(30 \mathrm{~mL} / 100 \mathrm{~L}$ of milk). Coagulation occurred within $16 \mathrm{~min}$ and the curd was manually cut to $2 \mathrm{~cm}$. Cooking was immediately started under agitation until a temperature of $42^{\circ} \mathrm{C}$ was reached. The curd was then ripened under whey until the $\mathrm{pH}$ for stretching (5.2) was reached $(2.8 \mathrm{~h}$ from the addition of rennet). Stretching and molding were performed manually to obtain pear-shaped cheeses of $500 \mathrm{~g}$ (fresh weight). After cooling in tap water $(1 \mathrm{~h})$, the cheese was salted in brine $(21 \% \mathrm{NaCl}, 2 \mathrm{~h})$ and ripened at 10 to $12^{\circ} \mathrm{C}$ at 75 to $80 \%$ relative humidity for $30 \mathrm{~d}$. At the end of ripening, the cheeses were vacuum-packaged and stored at $4^{\circ} \mathrm{C}$ for 2 to $3 \mathrm{~d}$, when sensory analyses were performed. Gross composition, $\mathrm{pH}$, and free amino acids were determined as described by Guidone et al. (2015).

\section{Sensory Analyses}

Ten panelists ( 3 males and 7 females) with a mean age of $25 \mathrm{yr}$ were recruited and selected according to the international standard ISO 8586-1 (ISO, 1993) and on the basis of their capacity to identify the 4 basic tastes (sourness, sweetness, bitterness, and saltiness), as suggested by Albenzio et al. (2013). Subsequently, panelists were trained in use of the scale (Stone and Sidel, 2004). Then, the judges, based on the available literature (Muir et al., 1995, 1996; Murray and Delahunty, 2000; Adhikari et al., 2003), developed a specific vocabulary for Scamorza cheese and agreed upon a consensus list of 18 attributes (Table 1). Subsequently, a proper and specific reference frame for assessor training was used (Table 1). The identification of reference standards required two 2-h sessions. For a reliable evaluation, at least 2 points of the scale were anchored to the reference material during the panel training.

A QDA method (Lawless and Heymann, 2010) was used to assess the products. Tests were performed at about $1000 \mathrm{~h}$ in sensory booths (ISO 8589; ISO, 1998) under red fluorescent lights to mask color differences in the samples, except during the evaluation of cheese 
Table 1. List of attributes used by the 10-member trained panel for Scamorza cheese sensory profiling

\begin{tabular}{|c|c|c|c|}
\hline Attribute & Low & High & Definition \\
\hline \multicolumn{4}{|l|}{ Appearance } \\
\hline Color uniformity & $30 \mathrm{~g}$ of Parmesan cheese seasoned $36 \mathrm{mo}$ & $30 \mathrm{~g}$ of Scamorza cheese & $\begin{array}{l}\text { Overall uniformity in color: presence of either } \\
\text { shades or tones reduces uniformity }\end{array}$ \\
\hline Yellowness & Scamorza cheese & Emmental & Overall intensity of yellow color \\
\hline Structure uniformity & Asiago cheese & Fontina cheese & $\begin{array}{l}\text { Overall uniformity in structure: presence of } \\
\text { either fissures or holes reduces uniformity }\end{array}$ \\
\hline \multicolumn{4}{|r|}{ 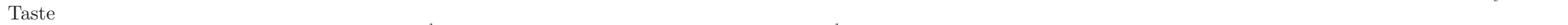 } \\
\hline Sourness & $8 \mathrm{~mL}$ of stock solution ${ }^{1} / 100 \mathrm{~mL}$-solution & $16 \mathrm{~mL}$ of stock solution ${ }^{1} / 100 \mathrm{~mL}$-solution & Fundamental taste associated with citric acid \\
\hline Sweetness & $8 \mathrm{~mL}$ of stock solution ${ }^{2} / 100 \mathrm{~mL}$-solution & $20 \mathrm{~mL}$ of stock solution ${ }^{2} / 100 \mathrm{~mL}$-solution & Fundamental taste associated with sucrose \\
\hline Bitterness & $4 \mathrm{~mL}$ of stock solution ${ }^{3} / 100 \mathrm{~mL}-$ solution & $8 \mathrm{~mL}$ of stock solution ${ }^{3} / 100 \mathrm{~mL}$-solution & Fundamental taste associated with quinine \\
\hline Saltiness & $1.5 \mathrm{~mL}$ of stock solution $/ 100 \mathrm{~mL}$-solution & $3 \mathrm{~mL}$ of stock solution ${ }^{4} / 100 \mathrm{~mL}$-solution & $\begin{array}{l}\text { Fundamental taste associated with sodium } \\
\text { chloride }\end{array}$ \\
\hline Umami & $5 \mathrm{~mL}$ of stock solution ${ }^{5} / 100 \mathrm{~mL}$-solution & $12 \mathrm{~mL}$ of stock solution ${ }^{5} / 100 \mathrm{~mL}$-solution & $\begin{array}{l}\text { Fundamental taste elicited by certain peptides } \\
\text { and nucleotides }\end{array}$ \\
\hline \multicolumn{4}{|r|}{ and nucteoutues } \\
\hline Milk & $30 \mathrm{~g}$ of Parmesan cheese seasoned $36 \mathrm{mo}$ & $\begin{array}{l}120 \mathrm{~g} \text { of Mozzarella cheese cut in blocks of about } 1 \mathrm{~cm}^{2} \\
\text { cross-sectional area }\end{array}$ & $\begin{array}{l}\text { Odor/flavor arising from milk at room } \\
\text { temperature }\end{array}$ \\
\hline Butter & $120 \mathrm{~g}$ of melted Ricotta cheese & $80 \mathrm{~g}$ of butter mixed with $40 \mathrm{~g}$ of Ricotta cheese & $\begin{array}{l}\text { Odor/flavor arising from butter at room } \\
\text { temperature }\end{array}$ \\
\hline Herbal & $120 \mathrm{~g}$ of melted Ricotta cheese & $30 \mathrm{~g}$ of Gorgonzola cheese & $\begin{array}{l}\text { Odor/flavor associated with blue cheese: sharp } \\
\text { with hints of herbs and butter }\end{array}$ \\
\hline \multicolumn{4}{|r|}{ 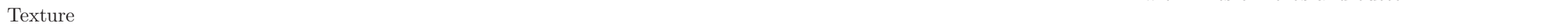 } \\
\hline Tenderness & $30 \mathrm{~g}$ of Parmesan cheese seasoned $36 \mathrm{mo}$ & $30 \mathrm{~g}$ of Ciliegina Mozzarella cheese & $\begin{array}{l}\text { Minimum force required to chew cheese sample: } \\
\text { the lower the force the higher the tenderness }\end{array}$ \\
\hline Grainy & $30 \mathrm{~g}$ of Crescenza cheese & $30 \mathrm{~g}$ of Parmesan cheese seasoned $36 \mathrm{mo}$ & Perception of course particles in mouth \\
\hline Oiliness & $30 \mathrm{~g}$ of Mozzarella cheese & $30 \mathrm{~g}$ of Emmental cheese & $\begin{array}{l}\text { Perception of the amount of fat released by the } \\
\text { product during mastication }\end{array}$ \\
\hline Cohesiveness & $30 \mathrm{~g}$ of Parmesan cheese seasoned $36 \mathrm{mo}$ & $30 \mathrm{~g}$ of Scamorza cheese & $\begin{array}{l}\text { The degree to which a cheese sample holds } \\
\text { together or adheres itself after chewing }\end{array}$ \\
\hline Springiness & $30 \mathrm{~g}$ of Emmental cheese & $30 \mathrm{~g}$ of Nodino Cheese & $\begin{array}{l}\text { Degree to which the product will return to its } \\
\text { original shape after being compressed between } \\
\text { the teeth }\end{array}$ \\
\hline Adhesiveness & $30 \mathrm{~g}$ of Mozzarella cheese & $30 \mathrm{~g}$ of Taleggio cheese & $\begin{array}{l}\text { The degree to which the chewed sample sticks to } \\
\text { the surface of the mouth and teeth }\end{array}$ \\
\hline Moisture & $30 \mathrm{~g}$ of Parmesan cheese seasoned $36 \mathrm{mo}$ & $30 \mathrm{~g}$ of Crescenza cheese & $\begin{array}{l}\text { Moisture released by the product in the mouth } \\
\text { during early mastication }\end{array}$ \\
\hline
\end{tabular}


appearance, when only white fluorescent lighting was used. In all tests, cheese slices (15-20 g) were served in random order. The serving temperature of the samples was of $13{ }^{\circ} \mathrm{C}$ (Hersleth et al., 2005). The attribute intensities were rated on 100-mm unstructured lines with anchor points at each end $(0=$ absent and $100=$ very strong). Panelists were asked to eat a slice of apple between samples to make the palate conditions similar for each sample. The interval between sample tasting was approximately $10 \mathrm{~min}$. To avoid sensory fatigue due to the number of samples, only 3 samples were evaluated in each session. The panelists evaluated 3 replications of each cheese product. In all, 4 sessions were performed to analyze all the samples.

\section{Consumer Testing}

Scamorza cheeses were evaluated for consumer acceptability (Kähkönen et al., 1996). A total of 87 consumers with an average age of $42 \mathrm{yr}$ and balanced for sex participated in the test. Each participant evaluated four 15 - to 20 -g slices $(2$ milk $\times 2$ starter types $)$ in a controlled sensory analysis laboratory. Cheese slices were served in random order. For each product, consumers expressed an overall liking and 3 specific likings corresponding to the following sensory inputs: appearance, taste/flavor, and texture. Consumers rated their likings on a 9-point hedonic scale labeled at the left end with "extremely unpleasant" ( end with "extremely pleasant" ( central point $($ score $=5)$ with "neither pleasant nor unpleasant" (Kähkönen et al., 1996).

\section{Statistical Analyses}

To verify panel performance in terms of reliability, sensory data were subjected to ANOVA with product ( 4 levels $=2$ starter types $\times 2$ milk types), assessors (10 levels), replications (3 levels), and their interactions as factors. A further ANOVA on these data with milk type (2 levels), starter type (2 levels) and their interactions as factors was performed. To identify the most liked product, acceptability data were analyzed by ANOVA, using milk type, starter type, and their interaction as factors. The PCA was performed (The Unscrambler X, version 10.1; Camo Software, Oslo, Norway) on the sensory profile and on cheese $\mathrm{pH}$, free amino acids, and $\mathrm{NaCl}$ content to study the relationship between sensory attributes and these parameters. The relationship between overall liking and attribute liking (appearance, taste/flavor, and texture) was analyzed by linear regression analysis according to the following equation: Overall liking $=\mathrm{k}_{0}+\mathrm{k}_{1}$ (attribute liking), where $\mathrm{k}_{0}$ are the $\mathrm{Y}$ intercepts and $\mathrm{k}_{1}$ are the individual slopes relating attribute liking to overall liking (raw slopes). Each consumer served as his/her own control. Significance of this linear equation was evaluated by correlation coefficient (r). Goodness of fit for individuals was measured by the Pearson coefficient of determination $\left(\mathrm{R}^{2}\right)$, which shows the percentage of variability that can be accounted for by a straight line.

Each individual generated 3 raw slopes (i.e., for appearance liking, taste/flavor liking, and texture liking vs. overall liking, respectively). The standard deviation (SD) measures the variability of that individual's raw slopes. The greater the SD of the 3 raw slopes, the more differentially one sensory attribute liking drives overall liking. The smaller the SD of the 3 raw slopes, the more equally the sensory attribute likings drive overall liking. The relationship between a set of 87 hedonic judgments (Y-matrix) and a set of 18 sensory properties corresponding to the $\mathrm{X}$-matrix (bitterness was excluded from the analysis as it was never perceived by the panelists during the QDA) was performed by PLS regression on standardized data using SIMCA-P 11 (Umetrics, Umea, Sweden) Umetrics package (Umetrics 2005). Two further PLS analyses were performed on 2 sub-groups of 29 and 13 consumers identified using the PLS performed on the entire group of 87 . Differences between the 2 groups in terms of age were assessed using a $t$-test, whereas frequencies of sex (2 sex levels $\times 2$ consumer groups) and education level (3 education levels $\times 2$ consumer groups) were evaluated using the $\chi^{2}$ test.

\section{RESULTS AND DISCUSSION}

\section{Sensory Profile of Scamorza Cheese}

A preliminary ANOVA showed that no product $x$ replication or product $x$ assessor interactions were significant $(P>0.05)$, indicating that both the training program and the reference frame were adequate to reach high reliability of the panel, as products were not evaluated differently in different replications or by different assessors. Based on these results, a second ANOVA was performed using milk type, starter type, and their interactions as factors. According to this analysis, milk type did not affect the sensory properties of the products with the exception of structure and color uniformity $(P$ $<0.05)$, sweetness $(P<0.05)$, and cohesiveness $(P<$ $0.10)$, possibly because of the small amount of Italian Jersey milk included in the mixed cheese. In fact, milk type did not affect cheese gross composition except for salt in moisture (see Guidone et al., 2015 for detailed results on gross composition). Scamorza cheese manufactured using F milk showed lower structure (33.3 \pm 3.4 vs $43.1 \pm 3.4$, respectively) and color $(33.7 \pm 3.5$ 
Table 2. Sensory profile of Scamorza cheese at $30 \mathrm{~d}$ of ripening (mean $\pm \mathrm{SE}$ ) as affected by type of starter

\begin{tabular}{|c|c|c|c|}
\hline \multirow[b]{2}{*}{ Attribute } & \multicolumn{2}{|c|}{ Starter ${ }^{1}$} & \multirow[b]{2}{*}{$P$-value } \\
\hline & ST & $\mathrm{ST}+\mathrm{A}$ & \\
\hline \multicolumn{4}{|l|}{ Appearance } \\
\hline Structure uniformity & $29.5 \pm 3.4$ & $46.9 \pm 3.4$ & $* * *$ \\
\hline Yellowness & $40.5 \pm 3.9$ & $38.7 \pm 3.9$ & NS \\
\hline Color uniformity & $27.2 \pm 3.5$ & $50.11 \pm 3.5$ & $* * *$ \\
\hline \multicolumn{4}{|l|}{ Odor/flavor } \\
\hline Butter & $70.6 \pm 3.0$ & $61.7 \pm 3.0$ & $*$ \\
\hline Milk & $9.5 \pm 2.9$ & $17.1 \pm 2.9$ & 0.06 \\
\hline Herbal & $44.3 \pm 3.8$ & $40.5 \pm 3.8$ & NS \\
\hline \multicolumn{4}{|l|}{ Taste } \\
\hline Saltiness & $47.4 \pm 3.8$ & $33.7 \pm 3.8$ & $*$ \\
\hline Sourness & $25.2 \pm 4.1$ & $36.2 \pm 4.2$ & * \\
\hline Sweetness & $49.2 \pm 3.9$ & $36.7 \pm 3.9$ & $*$ \\
\hline Umami & $51.5 \pm 3.8$ & $52.3 \pm 3.8$ & NS \\
\hline \multicolumn{4}{|l|}{ Texture } \\
\hline Adhesiveness & $61.8 \pm 3.7$ & $45.8 \pm 3.7$ & $* *$ \\
\hline Moisture & $63.2 \pm 3.3$ & $52.1 \pm 3.3$ & $*$ \\
\hline Springiness & $45.7 \pm 2.7$ & $36.3 \pm 2.7$ & $*$ \\
\hline Tenderness & $30.6 \pm 3.8$ & $15.1 \pm 3.8$ & $* *$ \\
\hline Cohesiveness & $45.4 \pm 4.0$ & $44.7 \pm 4.0$ & NS \\
\hline Oiliness & $20.4 \pm 3.1$ & $39.1 \pm 3.1$ & $* * *$ \\
\hline Grainy & $24.8 \pm 3.9$ & $37.4 \pm 3.9$ & $*$ \\
\hline
\end{tabular}

vs $43.6 \pm 3.5$, respectively) uniformity and tended to be yellower ( $44.8 \pm 3.9$ vs $34.3 \pm 3.9$, respectively; $P$ $<0.10)$ than the cheese made with mixed milk. In addition, panelists perceived higher sweetness intensity ( $47.8 \pm 3.9$ vs $38.0 \pm 3.9$, respectively) in F cheeses, although these products tended to show a lower cohesiveness $(40.0 \pm 4.0$ vs $50.1 \pm 4.0)$. Early studies of a breed effect on cheese sensory properties found no differences in Emmental cheeses made with milk of Holstein, Simmental, and Brown-Swiss cows (Rothenbuhler, 1972); similarly, Saint-Nectaire cheeses manufactured with milk from either Holstein or Montbéliarde showed no significant effect of breed on sensory profile, except for a yellower color in cheese from Holstein milk (Garel and Coulon, 1990). More recently, Martin et al. (2009) compared the sensory properties of Cantal cheese made using milk from Holstein or Montbéliarde cows and found lower firmness in the former due to its higher proteolysis and related possible higher protease activity (Bastian and Brown, 1996). The authors reported a higher yogurt/whey aroma and a higher sourness in Montbéliarde cheese, attributes consistent with their low $\mathrm{pH}$ and proteolysis.

The type of starter significantly affected many sensory attributes of Scamorza cheese (Table 2). Products processed with $\mathrm{ST}+\mathrm{A}$ showed higher structure and color uniformity $(P<0.001)$ compared with ST cheeses. In agreement, Albenzio et al. (2013) found an increment of color and structure uniformity in ewe milk Scamorza cheeses produced with the addition of probiotic cultures. In our study, the addition of an adjunct culture may have contributed to make microbial activity and metabolite accumulation more homogeneous in the cheese matrix. According to the theory of economics of information, appearance attributes are classified as search dimensions that can be experienced by consumers before purchasing. As Scamorza cheese is often sold as a portioned product, these attributes may play an important role in affecting consumer choice behavior (Wadhwani and McMahon, 2012).

The panelists perceived higher intensities of butter flavor $(P<0.05)$, saltiness $(P<0.05)$, and sweetness $(P<0.05)$ in $\mathrm{ST}$ cheeses. Although lactose possesses a low relative sweetness value, the higher perception of the attribute sweetness may be due to its higher residual concentration, as observed by Guidone et al. (2015) in ST cheese compared with ST+A, as a result of metabolism of lactose by the adjunct culture. Conversely, ST+A showed higher milk flavor $(P<0.01)$ and sourness $(P<0.05)$. Because of the low proteolysis and glycolysis induced by probiotic cultures, Albenzio et al. (2013) observed no relevant effects on the flavor of ewe milk Scamorza cheese, whereas other authors reported that incorporation of lactobacilli enhanced the sour-acid flavor of Cheddar cheese because of the complex peptidase system possessed by lactobacilli along 
with longer ripening used for this cheese (Lynch et al., 1999; El Soda et al., 2000). In our study, the higher sourness perceived for $\mathrm{ST}+\mathrm{A}$ cheeses may be related to their lower $\mathrm{pH}$ and higher L-lactic acid isomer content (Guidone et al., 2015). Cheese flavor is very complex, and numerous volatile and nonvolatile compounds are involved in its development because of proteolysis, lipolysis, and glycolysis activities resulting from bacterial intervention (Drake et al., 1996; Ong and Shah, 2009).

Starter type influenced many textural parameters. The ST cheeses showed higher adhesiveness $(P<0.01)$, moisture $(P<0.05)$, springiness $(P<0.05)$, and tenderness $(P<0.01)$ compared with $\mathrm{ST}+\mathrm{A}$ products, whereas $\mathrm{ST}+\mathrm{A}$ cheeses were perceived as more oily $(P$ $<0.001)$ and grainy $(P<0.05)$. Lower adhesiveness and higher grainy intensities were also found by Albenzio et al. (2013) in Scamorza cheeses manufactured with a probiotic adjunct. Similarly, Buriti et al. (2005) stated that the inclusion of Lactococcus spp. in cheeses significantly influenced textural parameters, leading to more-fragile cheeses, in addition to intense reductions of $\mathrm{pH}$ and increases in titratable acidity due to the production of lactic acid and other organic acids. As reported by Guidone et al. (2015), lower pH levels were also observed in the Scamorza cheese produced with the adjunct. Textural properties may affect cheese overall quality and consumer liking according to different sensory segments and play a fundamental role in the differentiation of cheese products and varieties (Foegeding et al., 2003).

The PCA bi-plot of Scamorza cheese sensory profile, and from cheese $\mathrm{pH}$, free amino acid, and $\mathrm{NaCl}$ content (Figure 1), provided a multivariate graphical representation of the product space showing the relationships between sensory features and other variables. The first 2 principal components of the PCA accounted for $57 \%$ of the variance in the data ( $36 \%$ for $\mathrm{PC} 1 ; 21 \%$ for $\mathrm{PC} 2$ ). In particular, $\mathrm{pH}(0.32)$, tenderness (0.32), saltiness (0.27), and sweetness (0.21) showed positive correlations with $\mathrm{PC} 1$, whereas color $(-0.35)$ and structure uniformity $(-0.30)$, grainy $(-0.33)$, sourness $(-0.29)$, milk $(-0.21)$, and oiliness $(-0.30)$ were negatively correlated with this axis. Conversely, $\mathrm{PC} 2$ showed high positive correlations with cohesiveness (0.34), butter (0.35), and umami (0.35) and negative correlations with $\mathrm{NaCl}$ content $(-0.35)$ and yellowness $(-0.42)$.

Although other authors (Hort et al., 1997) found a negligible influence of chemical parameters on sensory textural variables, in this study, PCA showed a positive relationship between $\mathrm{pH}$ and tenderness, sweetness, and

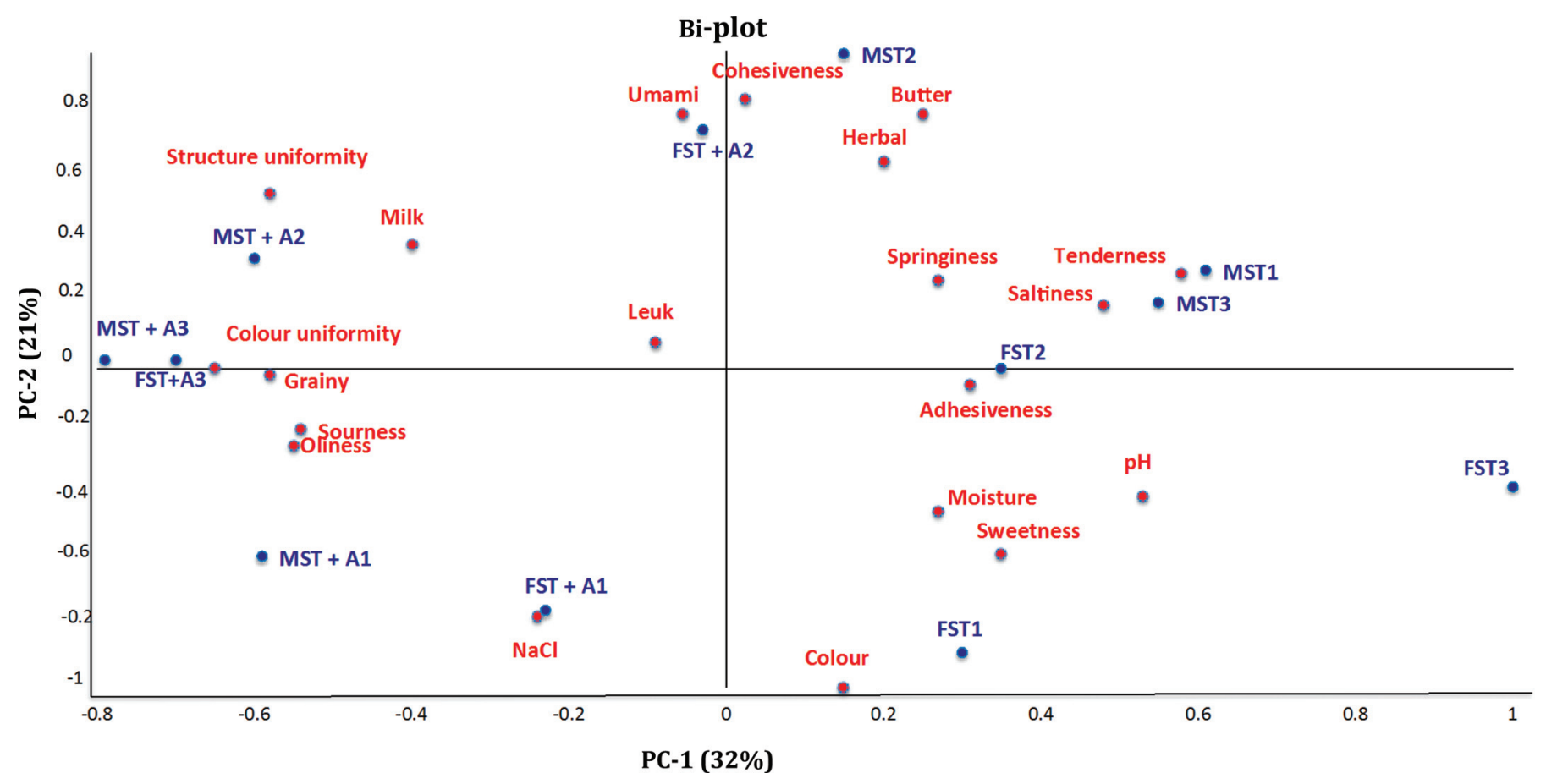

Figure 1. Principal component analysis (PCA) bi-plot (Unscrambler X, version 10.1; Camo) from Scamorza cheese sensory profile and from cheese $\mathrm{pH}$, free amino acids (Leuk), and $\mathrm{NaCl}$ content. Cheese was made with 2 types of milk, $\mathrm{F}=100 \%$ Italian Friesian cattle; $\mathrm{M}=90 \% \mathrm{~F}+$ $10 \%$ Jersey, and 2 types of starter culture, ST = a defined Streptococcus thermophilus starter culture (Lyofast ST051, Sacco Srl, Cadorago, Italy) used alone, and ST+A = ST + an adjunct containing Lactococcus lactis, Lactobacillus paracasei, and Lactobacillus helveticus. The 4 treatments were FST, FST+A, MST, MST+A; for each product, numerals $(1,2,3)$ indicate replications. Color version available online. 
saltiness, whereas a negative correlation was observed between $\mathrm{pH}$ and grainy, oiliness, color and structure uniformity, sourness and milk (Figure 1).

Leiva and Figueroa (2010) found that some sensory properties such as cohesiveness, firmness, and deformability were closely related to chemical parameters (i.e., $\mathrm{pH}$, moisture, and salt content) in determining the perception of the sensory structure of Chanco cheese. As also observed in our study, Pereira et al. (2006) found a relationship between sensory firmness, adhesiveness, and chemical data. According to Lawlor et al. (2001), $\mathrm{pH}$ influences cheese texture, because $\mathrm{pH}$ changes are directly related to calcium content and protein network. Those authors, in fact, found a negative correlation between $\mathrm{pH}$ and sensory firmness, whereas $\mathrm{pH}$ was positively related to moisture and oiliness. Heller et al. (2003) stated that the rate and extent of acidification have a major effect on cheese texture via demineralization of the casein micelles. The more intense the production of lactic acid by microorganisms, the higher the decrease in calcium bound to casein and the more brittle the texture of cheeses (Fox and McSweeney, 1998). In addition, $\mathrm{pH}$ can play a key role in flavor development as it influences growth of nonstarter lactic acid bacteria in Cheddar and Gouda cheeses and the dissociation and odor activity of volatile compounds in several different cheeses (Lawlor et al., 2001).

Salt content had a negative relationship with tenderness (Figure 1). According to Karimi et al. (2012), salt content can affect the textural properties of cheese through its effect on microbial activity (acidification and proteolysis), its direct effect on the protein matrix of cheese by decreasing the volume of protein particles (Gomes and Malcata, 1998), and its influence on free water content. The decreased proteolysis related to high salt content can result in a more intact protein network and therefore increased hardness. A decrease in moisture content or an increase in salt content may reduce the hydration of protein and restrict freedom of movement, thus decreasing the viscous properties and the deformability of the cheese.

Although the negative relationship between saltiness and salt content (Figure 1) may seem inconsistent, salt release and perception in the mouth is complex and is related to texture and moisture content in food (Davidson et al., 1998, 2000). In particular, a close relationship exists between food texture and masticatory behavior (Kohyama et al., 2002, 2005; Peyron et al., 2004), and the quantity of salt released and perceived from a soft cheese is greater than that released and perceived from a hard cheese (Phan et al., 2008). Accordingly, in our bi-plot depiction, saltiness was positively correlated with tenderness and moisture (Figure 1).

Results of the QDA were confirmed by PCA. Our bi-plot representation gives a clear discrimination of the products according to the starter type (Figure 1). On the positive side of the first component are the ST cheeses characterized by higher tenderness, butter flavor, sweetness, moisture, and saltiness. Conversely, $\mathrm{ST}+\mathrm{A}$ Scamorza cheeses are placed on the negative side of the first component along with structure uniformity, milk, sourness, and oiliness. These products also showed a lower pH (Guidone et al., 2015).

\section{Consumer Testing}

The results of the hedonic test on 87 consumers are depicted in Table 3 . All products were rated at scores well above the neutral point $(5=$ neither pleasant nor unpleasant). These results show that Scamorza from both milk types and both starter types were perceived as being characterized by a good eating quality. Milk type did not influence overall liking or liking in terms of taste/flavor, texture, and appearance.

In contrast, Scamorza cheeses differed significantly in relation to starter type. Cheeses processed with traditional starter (ST) showed higher values for overall $(P<0.05)$, appearance $(P<0.05)$, taste/flavor $(P<$

Table 3. Hedonic test of Scamorza cheese at $30 \mathrm{~d}$ of ripening (means \pm SE) as affected by type of starter and type of milk

\begin{tabular}{|c|c|c|c|c|c|c|}
\hline \multirow[b]{2}{*}{ Attribute } & \multicolumn{2}{|c|}{ Starter $^{1}(\mathrm{~S})$} & \multicolumn{2}{|c|}{ Type of milk ${ }^{2}(\mathrm{TM})$} & \multicolumn{2}{|c|}{$P$-value } \\
\hline & ST & $\mathrm{ST}+\mathrm{A}$ & $\mathrm{F}$ & M & S & TM \\
\hline Overall liking & $6.70 \pm 0.11$ & $6.38 \pm 0.11$ & $6.56 \pm 0.11$ & $6.52 \pm 0.11$ & $*$ & NS \\
\hline Appearance & $6.64 \pm 0.11$ & $6.27 \pm 0.11$ & $6.50 \pm 0.11$ & $6.42 \pm 0.11$ & * & NS \\
\hline Taste/flavor & $6.95 \pm 0.11$ & $6.44 \pm 0.11$ & $6.60 \pm 0.11$ & $6.80 \pm 0.11$ & ** & NS \\
\hline Texture & $7.02 \pm 0.09$ & $6.60 \pm 0.09$ & $6.74 \pm 0.09$ & $6.88 \pm 0.09$ & $* *$ & NS \\
\hline
\end{tabular}

${ }^{1}$ Starters: ST = a defined Streptococcus thermophilus starter culture, Lyofast ST051 (Sacco Srl, Cadorago, Italy) used alone; $\mathrm{ST}+\mathrm{A}=\mathrm{ST}+$ an adjunct containing Lactococcus lactis, Lactobacillus paracasei, and Lactobacillus helveticus.

${ }^{2}$ Type of milk: $\mathrm{F}=100 \%$ Italian Friesian; $\mathrm{M}=90 \% \mathrm{~F}+10 \%$ Jersey.

${ }^{*} P<0.05 ;{ }^{* *} P<0.01$. 


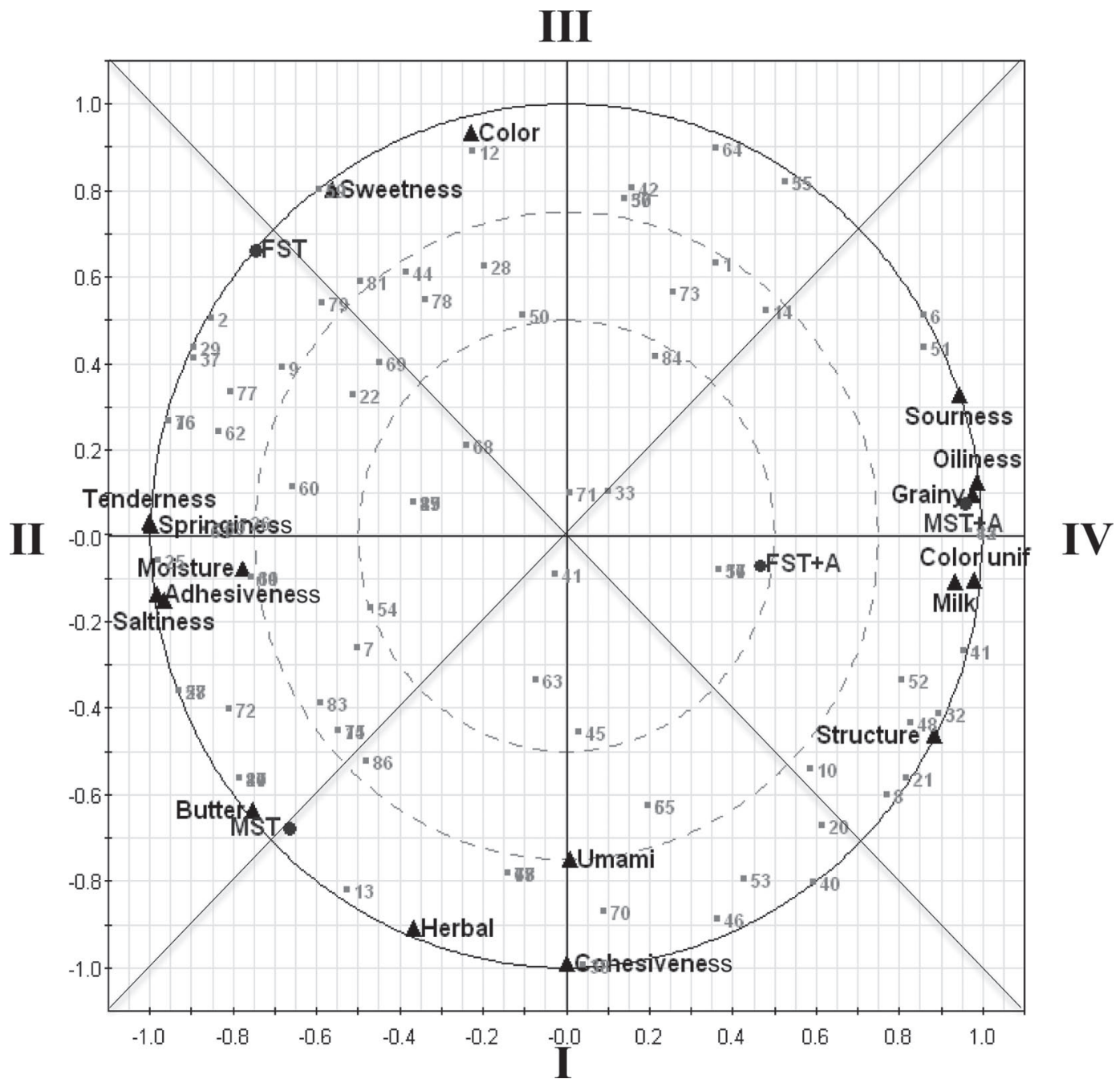

Figure 2. Correlation circle of the products (triangles), characteristics (circles), and judges, and construction of the judge clustering using the 2 bisectors (the 4 groups are indicated by I, II, III, and IV). Cheese was made with 2 types of milk, F = 100\% Italian Friesian cattle; M $=90 \% \mathrm{~F}+10 \%$ Jersey, and 2 types of starter culture, ST = a defined Streptococcus thermophilus starter culture (Lyofast ST051, Sacco Srl, Cadorago, Italy) used alone, and $\mathrm{ST}+\mathrm{A}=\mathrm{ST}+$ an adjunct containing Lactococcus lactis, Lactobacillus paracasei, and Lactobacillus helveticus. The 4 treatments were FST, FST+A, MST, MST+A.

$0.01)$, and texture $(P<0.01)$ liking compared with $\mathrm{ST}+\mathrm{A}$ products.

In a previous study on Cheddar cheese, the incorporation of probiotic bacteria (addition of Lactobacillus casei and a mixture of Lactobacillus acidophilus 4962, Bifidobacterium longum 1941, and L. casei 279) reduced flavor acceptability (Ong et al., 2007). In addition, these products received higher scores for bitterness, sour-acid taste, and vinegary taste compared with those without probiotic bacteria (Ong et al., 2007). These results support previous studies reporting the enhancement of bitterness related to the addition of lactobacilli (El Soda et al., 2000) and their complex peptidases system. Similarly, Gomes et al. (2011) found lower scores of liking of Minas fresh cheeses with increasing amounts of $L$. acidophilus $(0,0.4$, or $0.8 \mathrm{~g} / \mathrm{L}$ of milk) compared with control products. In particular, probiotic cheeses showed lower scores of liking for appearance, aroma, and texture because of the lower $\mathrm{pH}$ values and higher production of organic acids induced by the microbial metabolism.

Other authors have observed that the addition of adjunct strains can improve flavor and other sensory attributes (de Souza et al., 2008). Sato et al. (2012) found significant improvements in flavor and texture liking using a commercial starter culture combined with Lactobacillus strains (L. plantarum or L. helveticus) as adjunct cultures for the manufacture of Prato cheese. The authors attributed the differences in perceived flavor and texture to the higher levels of proteolysis oc- 
Table 4. SIMCA-P software (Umetrics, Umea, Sweden) output: correlations (Corr) between Y of the 29 judges and the first 2 partial least squares (PLS) components (PC1 and PC2) of the PLS regression of $\mathrm{Y}$ on X (group II: 29 consumers showing a higher liking for Scamorza cheese produced using a defined Streptococcus thermophilus starter culture)

\begin{tabular}{|c|c|c|}
\hline Judge & $\begin{array}{c}\text { Corr } \\
(\mathrm{Y}, \mathrm{PC} 1)\end{array}$ & $\begin{array}{c}\text { Corr } \\
(\mathrm{Y}, \mathrm{PC} 2)\end{array}$ \\
\hline 2 & 0.25 & 0.24 \\
\hline 7 & 0.15 & -0.154 \\
\hline 9 & 0.20 & 0.224 \\
\hline 15 & 0.17 & -0.24 \\
\hline 16 & 0.28 & 0.14 \\
\hline 19 & 0.23 & 0.02 \\
\hline 22 & 0.15 & 0.20 \\
\hline 24 & 0.24 & -0.23 \\
\hline 25 & 0.30 & -0.00 \\
\hline 26 & 0.23 & -0.00 \\
\hline 27 & 0.28 & -0.15 \\
\hline 29 & 0.26 & 0.22 \\
\hline 31 & 0.23 & 0.00 \\
\hline 37 & 0.26 & 0.19 \\
\hline 39 & 0.25 & -0.00 \\
\hline 47 & 0.24 & -0.23 \\
\hline 58 & 0.28 & -0.15 \\
\hline 60 & 0.20 & 0.10 \\
\hline 61 & 0.26 & -0.00 \\
\hline 62 & 0.25 & 0.15 \\
\hline 66 & 0.23 & 0.00 \\
\hline 69 & 0.13 & 0.23 \\
\hline 72 & 0.25 & -0.15 \\
\hline 74 & 0.17 & -0.24 \\
\hline 76 & 0.28 & 0.14 \\
\hline 77 & 0.24 & 0.14 \\
\hline 79 & 0.171 & 0.23 \\
\hline 80 & 0.24 & -0.23 \\
\hline 83 & 0.18 & -0.13 \\
\hline
\end{tabular}

curring in the cheese with adjunct cultures. Proteolysis, in fact, plays a central role in the determination of the typical sensory characteristics of a cheese.

Regression of consumer acceptability against analytical sensory data can explain which input drives the acceptance for a specific product (Ward et al., 1999; Moskowitz, 2001). To determine the drivers of liking in terms of sensory input, we analyzed the relationship between overall liking and liking of specific sensory input (appearance, taste/flavor, and texture) by linear regression analysis. Significance of this linear equation was evaluated by correlation coefficient; consumers showing no significant correlation for all the sensory properties were not included in the analysis. No significant differences were observed between texture, appearance, and taste/flavor. Therefore, none of them prevailed in driving the overall liking of Scamorza cheese. However, as the raw slopes of the 3 inputs were high $(0.74,0.87$, and 0.78 , for appearance, texture, and taste/flavor, respectively), they all may be considered important in affecting Scamorza cheese liking. For instance, Liggett and Delwiche (2008) gave relevance to the effect of flavor on consumer liking of Swiss cheese, whereas another study showed that appearance significantly affected consumer preference (Murray and Delahunty, 2000).

\section{Relationship Between Hedonic Judgments and Product Characteristics}

The PLS regression of the 87 judges (Y) on the 18 sensory variables $(\mathrm{X})$ led to the products $\times$ characteristics $\times$ judgments map shown in Figure 2. This is the correlation circle between the products, characteristics, and judgments variables and the first 2 PLS components. Circles drawn in the map represent the correlation circles. Usually, the first component is globally significant and describes the liking of the majority of consumers. The other components are more local and describe the liking of smaller groups of assessors. The first component is also probably more stable than the following components on a new sample (Tenenhaus et al., 2005).

On PC1, $65 \%$ of variance of X explained $37 \%$ of variance of $\mathrm{Y}$; on $\mathrm{PC} 2,28 \%$ of the variance of $\mathrm{X}$ explained $26 \%$ of $\mathrm{Y}$. Thus, the variance of Y explained by the first $2 \mathrm{PC}$ of $\mathrm{Y}$ was $63 \%$. The correlations between $\mathrm{Y}$ and the $2 \mathrm{PC}$ reflect the portion of liking of judge $\mathrm{k}$ explainable by the characteristics $\mathrm{X}$ of the products.

Figure 2 shows that assessors had very different opinions on products and that some assessors' liking cannot be related to product characteristics because they are located in the center of the graphical display. According to Tenenhaus et al. (2005), it is not useful to consider these assessors in the clustering because the aim of the analysis is to identify groups that can be interpreted clearly in terms of characteristics of the products rather than an exhaustive description of the

Table 5. SIMCA-P software (Umetrics, Umea, Sweden) output: correlations (Corr) between $\mathrm{Y}$ of the 13 judges and the first 2 partial least squares (PLS) components (PC1 and PC2) of the PLS regression of $\mathrm{Y}$ on $\mathrm{X}$ (group IV: 13 consumers showing a higher liking for Scamorza cheese produced using a defined Streptococcus thermophilus starter culture + an adjunct containing Lactococcus lactis, Lactobacillus paracasei, and Lactobacillus helveticus)

\begin{tabular}{lcr}
\hline Judge & $\begin{array}{c}\text { Corr } \\
(\mathrm{Y}, \mathrm{PC} 1)\end{array}$ & $\begin{array}{c}\text { Corr } \\
(\mathrm{Y}, \mathrm{PC} 2)\end{array}$ \\
\hline 3 & 0.28 & 0.16 \\
4 & 0.30 & 0.09 \\
6 & 0.25 & -0.26 \\
8 & 0.25 & 0.25 \\
10 & 0.19 & 0.22 \\
11 & 0.30 & 0.09 \\
21 & 0.26 & 0.23 \\
32 & 0.28 & 0.16 \\
43 & 0.29 & -0.04 \\
48 & 0.26 & 0.17 \\
51 & 0.25 & -0.23 \\
52 & 0.25 & 0.12 \\
82 & 0.29 & -0.04 \\
\hline
\end{tabular}




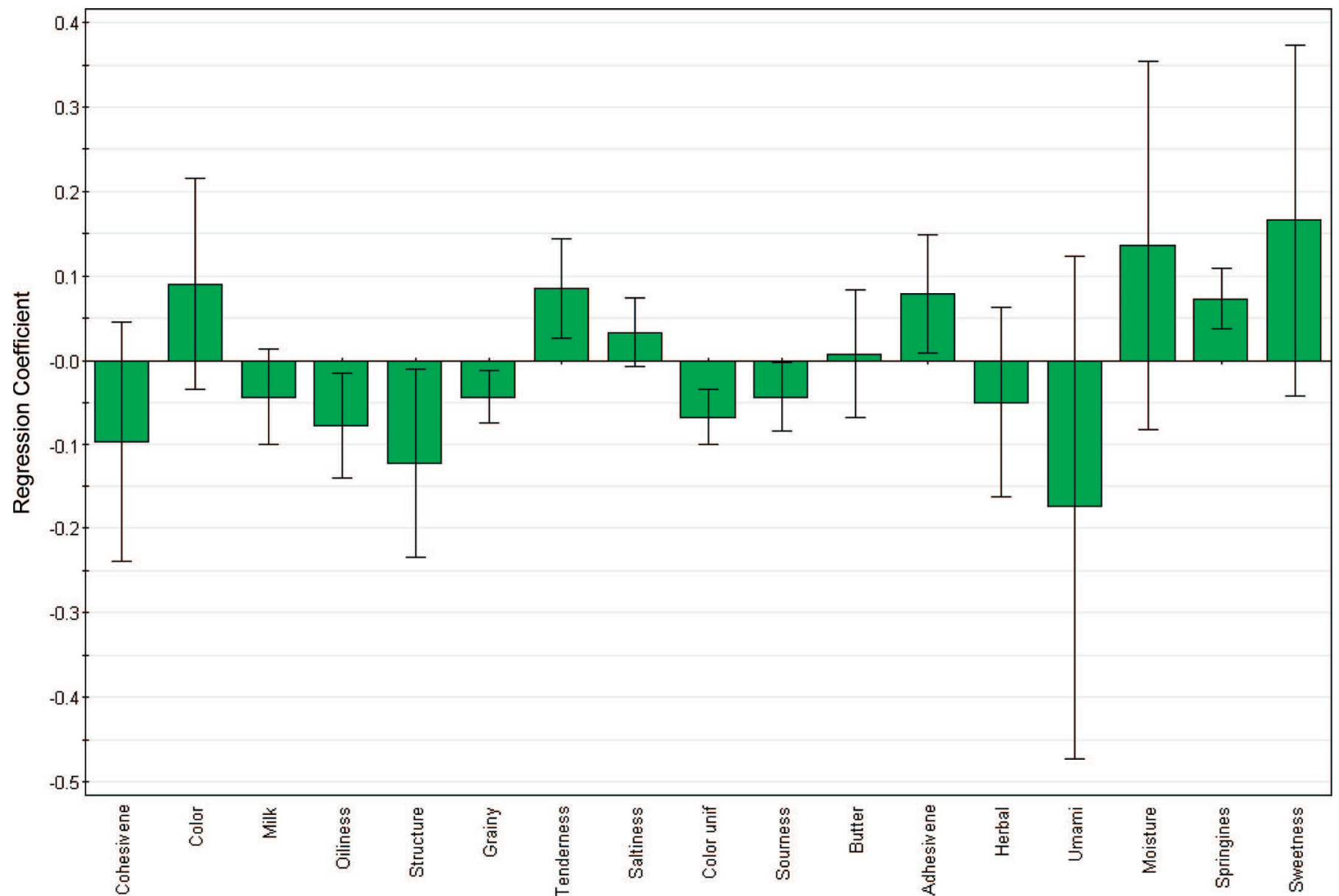

Figure 3. Significant characteristics [95\% jackknife confidence intervals of the partial least squares (PLS) regression coefficients in the PLS regression of component $\mu 1$ on X] for group II (29 consumers showing a higher liking for Scamorza cheese produced using a defined Streptococcus thermophilus starter culture; Lyofast ST051, Sacco Srl, Cadorago, Italy) alone. Color version available online.

population. Therefore, we decided to eliminate from the analysis assessors with an $\mathrm{R}^{2} \leq 0.20$, located in the center, out of the correlation circles. These consumers represented $16.1 \%$ of the population.

To cluster the consumers based on their liking as explained by the product characteristics, we used their coordinates in the plan. The plan was divided into 4 areas bordered by the 2 bisectors, thus obtaining the 4 groups of consumers (Figure 2). Groups I, II, III, and IV represent, respectively, 16.1, 33.3, 19.5, and $14.9 \%$ of the consumers.

To analyze more precisely a PLS component, it is useful to analyze each side of the component separately. The interpretation of each dimension can be done with more precision by analyzing each group of consumers separately. In particular, liking analysis was performed on groups II and IV as they could be related to the products, although no significant differences between these 2 groups of consumers were observed in terms of age $(t=0.71, P=0.48)$, sex $\left(\chi^{2}=0.02 ; P=0.90\right)$, and education level $\left(\chi^{2}=3.19 ; P=0.20\right)$.

The quality of the PLS regression of the Y of the 29 judges in group II alone on the 18 characteristics X of the products with 2 components was higher than the previous regression performed on all consumers, as the present analysis explained $63 \%$ of the variation. The map representing the correlation between the variables and the 2 components is not shown, as it is virtually an extract of Figure 2. The correlations between each assessor and the 2 PLS components were very similar, and for $\mathrm{PC} 1$ (total explained variance in $\mathrm{Y}$ is $73 \%$ ) they were positive (Table 4). This group of consumers preferred cheeses obtained with standard starter (FST and MST) while rejecting the others (FST+A and MST+A). Thus, the properties driving the liking of group II were those with high positive values such as tenderness, adhesiveness, springiness, and moisture in terms of texture, butter in terms of odor/flavor, 


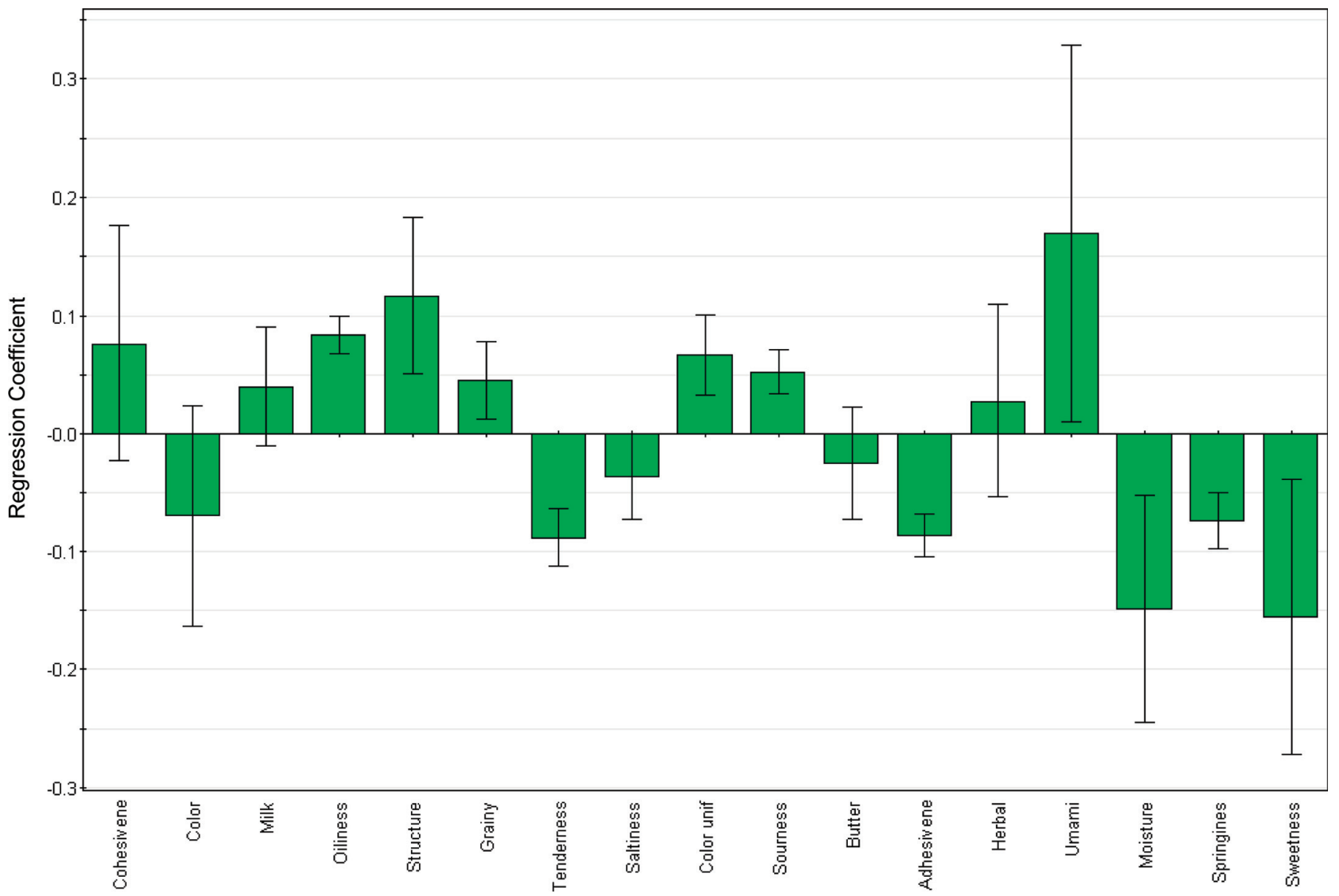

Figure 4. Significant characteristics [95\% jackknife confidence intervals of the partial least squares (PLS) regression coefficients in the PLS regression of component $\mu 1$ on X] for group IV [13 consumers showing a higher liking for Scamorza cheese produced using a defined Streptococcus thermophilus starter culture (Lyofast ST051, Sacco Srl, Cadorago, Italy) + an adjunct containing Lactococcus lactis, Lactobacillus paracasei, and Lactobacillus helveticus]. Color version available online.

and sweetness in terms of taste (Figure 3); in contrast, the same consumers rejected characteristics showing negative values, such as grainy and oiliness in terms of texture, milk in terms of odor/flavor, sourness in terms of taste, and color uniformity in terms of appearance.

The quality of the PLS regression of the $\mathrm{Y}$ of the 13 judges in group IV alone on the 18 characteristics $\mathrm{X}$ of the products with 2 components was higher than the regression performed on all consumers (total explained variance in $\mathrm{Y}$ is $92 \%$ ). As for group II, the map that represents the correlation between the variables and the 2 components is not shown, because it is essentially an extract of Figure 2. The correlations between each assessor and the 2 PLS components were very similar, and for PC1, they were positive (Table 5 ). These consumers preferred cheeses processed with Strep. thermophilus plus the adjunct culture (FST+A and MST $+\mathrm{A}$ ), characterized by specific attributes of cohesiveness and oiliness (texture), milk (odor/flavor), sourness (taste), and structure and color uniformity (appearance; Figure 4).

The present study clustered consumers in 2 main groups with specific likes and dislikes toward products. These segments can be distinguished for effective marketing or product development, as suggested by Drake (2007) in a review study on dairy products. In particular, the liking of group IV for cheeses produced using an adjunct culture and characterized by specific attributes encourages studies focusing on a further development of short-ripened products.

\section{CONCLUSIONS}

In the present study, we produced and validated a specific frame of reference and a specific quantitative vocabulary for panel training and Scamorza cheese sensory evaluation. Such tools should be applied to constantly monitor the quality of Scamorza cheese 
obtained with or without the use of adjunct cultures. Mixing a small amount of Jersey milk (up to 20\%) with Friesian milk did not markedly change the sensory quality of cheese. Sensory analysis was able to differentiate the 2 main product categories, that obtained using ST and that obtained using $\mathrm{ST}+\mathrm{A}$, based on flavor, texture and appearance attributes. In particular, the adjunct culture induced higher structure and color uniformity, grainy texture, milk flavor and sourness because of the higher microbial activity, leading to greater accumulation of microbial metabolites in the cheese. Although all products received hedonic scores well above the neutral point, the use of an adjunct culture somewhat reduced the overall acceptability of the product. However, it seems promising that a sub-group of consumers preferred products with these characteristics. In addition, changes in the adjunct (exclusion of Lc. lactis) and process characteristics (leading to an increment in moisture) could be used to fulfill the sensory requirements of a wider range of consumers and increase overall liking. Therefore, further studies for the development of short-ripened products based on the use of adjunct cultures should be conducted to promote product differentiation and meet the sensory requirements of particular segments of consumers.

\section{ACKNOWLEDGMENTS}

Research was co-funded by European Union and Regione Basilicata (FESR Misura 124HC QUALIFORM).). Thanks are due to A. M. Riviezzi (Scuola di Scienze Agrarie, Forestali, Alimentari ed Ambientali, Università degli Studi della Basilicata, Potenza, Italy) for expert technical assistance in sensory analysis.

\section{REFERENCES}

Adhikari, K., H. Heymann, and H. E. Huff. 2003. Textural characteristics of low fat, full fat and smoked cheeses: Sensory and instrumental approaches. Food Qual. Prefer. 14:211-218.

Albenzio, M., A. Santillo, M. Caroprese, A. Braghieri, A. Sevi, and F Napolitano. 2013. Composition and sensory profiling of probiotic Scamorza ewe milk cheese. J. Dairy Sci. 96:2792-2800.

Ayad, E., A. Verheul, J. Wouters, and G. Smit. 2000. Application of wild starter cultures for flavour development in pilot plant cheese making. Int. Dairy J. 10:169-179.

Bastian, E. D., and R. J. Brown. 1996. Plasmin in milk and dairy products: An update. Int. Dairy J. 6:435-457.

Braghieri, A., A. Girolami, A. Carlucci, N. Piazzolla, A. M. Riviezzi, and F. Napolitano. 2009. Sensory properties affecting pcceptability of "Bresaola" from Podolian young bulls. J. Sens. Stud. 24:677-697.

Braghieri, A., A. Girolami, A. M. Riviezzi, N. Piazzolla, and F. Napolitano. 2014. Liking of traditional cheese and consumer willingness to pay. Ital. J. Anim. Sci. 13:155-162.

Braghieri, A., N. Piazzolla, A. Carlucci, E. Monteleone, A. Girolami, and F. Napolitano. 2012. Development and validation of a quantitative frame of reference for meat sensory evaluation. Food Qual. Prefer. 25:63-68
Buriti, F. C. A., J. S. da Rocha, and S. M. I. Saad. 2005. Incorporation of Lactobacillus acidophilus in Minas fresh cheese and its implications for textural and sensorial properties during storage. Int. Dairy J. 15:1279-1288.

Carpino, S., J. Horne, C. Melilli, G. Licitra, D. M. Barbano, and P. J. Van Soest. 2004. Contribution of native pasture to the sensory properties of Ragusano cheese. J. Dairy Sci. 87:308-315.

Coulon, J. B., A. Delacroix-Buchet, B. Martin, and A. Pirisi. 2004. Relationships between ruminant management and sensory characteristics of cheeses: A review. Lait 84:221-241.

Davidson, J. M., R. S. T. Linforth, T. A. Hollowood, and A. J. Taylor. 2000. Release of non-volatile flavor compounds in vivo. Pages 99-111 in Flavor Release. D. D. Roberts, and A. J. Taylor, ed. American Chemical Society, Washington, DC.

Davidson, J. M., R. S. T. Linforth, and A. J. Taylor. 1998. In-mouth measurement of $\mathrm{pH}$ and conductivity during eating. J. Agric Food Chem. 46:5210-5214.

de Souza, C. H. B., F. C. A. Buriti, J. H. Behrens, and S. M. I. Saad. 2008. Sensory evaluation of probiotic Minas fresh cheese with Lactobacillus acidophilus added solely or in co-culture with a thermophilic starter culture. Int. J. Food Sci. Technol. 43:871-877.

Drake, M. A. 2007. Invited review: Sensory analysis of dairy foods J. Dairy Sci. 90:4925-4937. http://dx.doi.org/10.3168/jds.20070332 .

Drake, M. A., T. D. Boylston, K. D. Spencec, and B. G. Swansod. 1996. Chemical and sensory effects of a Lactobacillus adjunct in Cheddar cheese. Food Res. Int. 29:381-387.

El Soda, M., S. Madkor, and P. S. Tong. 2000. Adjunct cultures: Recent developments and potential significance to the cheese industry. J. Dairy Sci. 83:609-619.

Esposito, G., F. Masucci, F. Napolitano, A. Braghieri, R. Romano, N. Manzo, and A. Di Francia. 2014. Fatty acid and sensory profiles of Caciocavallo cheese as affected by management system. J. Dairy Sci. 97:1918-1928.

Foegeding, E. A., J. Brown, M. Drake, and C. R. Daubert. 2003. Sensory and mechanical aspects of cheese texture. Int. Dairy J. 13:585-591.

Fox, P. F., and P. L. H. McSweeney. 1998. Dairy Chemistry and Biochemistry. Blackie Academic \& Professional, London, UK.

Frister, H., M. Michaelis, T. Schwerdtfeger, D. M. Folkenberg, and N. K. Sorensen. 2000. Evaluation of bitterness in Cheddar cheese. Milchwissenschaft 55:691-695.

Garel, J. P., and J. B. Coulon. 1990. Effect de l'alimentation et de la race des vaches sur les fabrications de fromage d'Auvergne de Saint-Nectaire, INRA. Prod. Anim. 3:127-136.

Gobbetti, M., M. Morea, F. Baruzzi, M. Corbo, A. Matarante, T. Considine, R. Di Cagno, T. Guinee, and P. F. Fox. 2002. Microbiological, compositional, biochemical and textural characterisation of Caciocavallo Pugliese cheese during ripening. Int. Dairy J. $12: 511-523$.

Gomes, A. A., S. P. Braga, A. G. Cruz, R. S. Cadena, P. C. B. Lollo, C. Carvalho, J. Amaya-Farfán, J. A. F. Faria, and H. M. A. Bolin. 2011. Effect of the inoculation level of Lactobacillus acidophilus in probiotic cheese on the physicochemical features and sensory performance compared with commercial cheeses. J. Dairy Sci. 94:4777-4786

Gomes, A. M. P., and F. X. Malcata. 1998. Development of probiotic cheese manufactured from goat milk: Response surface analysis via technological manipulation. J. Dairy Sci. 81:1492-1507.

Guidone, A., A. Braghieri, S. Cioffi, S. Claps, F. Genovese, G. Morone, F. Napolitano, and E. Parente. 2015. Effect of adjuncts on microbiological and chemical properties of Scamorza cheese. J. Dairy Sci. 98:1467-1478. 10.3168/jds.2014-8554.

Heller, K. J., W. Bockelmann, J. Schrezenmeir, and M. deVrese. 2003. Cheese and its potential as a probiotic food. Pages 203-225 in Handbook of Fermented Functional Foods. E. R. Farnworth, ed. CRC Press, Boca Raton, FL.

Hersleth, M., O. Ueland, H. Allain, and T. Naes. 2005. Consumer acceptance of cheese, influence of different testing conditions. Food Qual. Prefer. 16:103-110. 
Hort, J., G. Grys, and J. Woodman. 1997. The relationships between the chemical, rheological and textural properties of Cheddar cheese. Lait 77:587-600.

ISO (International Organization for Standardization). 1993. ISO 8586-1: Sensory analysis: General guidance for the selection, training and monitoring of assessors: Selected Assessors. ISO, Geneva, Switzerland.

ISO (International Organization for Standardization). 1998. ISO 8589: Sensory analysis: General guidance for the design of test rooms. ISO, Geneva, Switzerland.

Kähkönen, P., H. Tuorila, and H. Rita. 1996. How information enhances acceptability of a low-fat spread. Food Qual. Prefer. 7:87-94.

Karimi, S., R. Sohrabvandi, and A. M. Mortazavian. 2012. Review article: Sensory characteristics of probiotic cheese. Comp. Rev. Food Sci. Food Safety 11:437-452.

Kohyama, K., E. Hatakeyama, H. Dan, and T. Sasaki. 2005. Effects of sample thickness on bite force for raw carrots and fish gels. J. Texture Stud. 36:157-173.

Kohyama, K., L. Mioche, and J. F. Martin. 2002. Chewing patterns of various texture foods studied by electromyography in young and elderly populations. J. Texture Stud. 33:269-283.

Lawless, H. T., and H. Heymann. 2010. Sensory Evaluation of Food: Principles and Practices. Chapman and Hall, Springer Publishing, New York, NY.

Lawlor, J. B., C. M. Delahunty, M. G. Wilkinson, and J. Sheehan. 2001. Relationships between the sensory characteristics, neutral volatile composition and gross composition of ten cheese varieties. Lait 81:487-507.

Lee, B., K. Kilcawley, J. Hannon, S. Park, M. Wilkinson, and T. P. Beresford. 2007. The use of viable and heat-shocked Lactobacillus helveticus DPC 4571 in enzyme-modified cheese production. Food Biotechnol. 21:129-143.

Leiva, J., and H. Figueroa. 2010. Texture of Chanco cheese: Projection of a sensory map based on multivariate analysis. Cienc. Inv. Agric. 37:85-91.

Liggett, R. E. M. A. D., and J. F. Delwiche. 2008. Impact of flavor attributes on consumer liking of Swiss cheese. J. Dairy Sci. 91:466-476.

Lynch, C. M., D. D. Muir, J. M. Banks, P. L. H. McSweeney, and P. F. Fox. 1999. Influence of adjunct cultures of Lactobacillus paracasei ssp. paracasei or Lactobacillus plantarum on Cheddar cheese ripening. J. Dairy Sci. 82:1618-1628.

Martin, B., D. Pomiès, P. Pradel, I. Verdier-Metz, and B. Rémond. 2009. Yield and sensory properties of cheese made with milk from Holstein or Montbéliarde cows milked twice or once daily. J. Dairy Sci. 92:4730-4737.

Moskowitz, H. R. 2001. Margarine: The drivers of liking and image. J. Sens. Stud. 16:53-72. http://dx.doi.org/10.1111/j.1745459X.2001.tb00290.x.

Muir, D. D., J. M. Banksa, and E. A. Hunter. 1996. Sensory properties of cheddar cheese: Effect of starter type and adjunct. Int. Dairy J. 6:407-423.

Muir, D. D., E. A. Hunter, J. M. Banks, and D. S. Horne. 1995. Sensory properties of hard cheese: Identification of key attributes. Int. Dairy J. 5:157-177.

Murray, J. M., and C. M. Delahunty. 2000. Mapping consumer preference for the sensory and packaging attributes of Cheddar cheese. Food Qual. Prefer. 11:419-435.
Ong, L., A. Henriksson, and N. P. Shah. 2007. Chemical analysis and sensory evaluation of cheddar cheese produced with Lactobacillus acidophilus, Lb. casei, Lb. paracasei or Bifidobacterium sp. Int. Dairy J. 17:937-945

Ong, L., and N. P. Shah. 2009. Probiotic Cheddar cheese: Influence of ripening temperatures on survival of probiotic microorganisms, cheese composition and organic acid profiles. Lebenson. Wiss. Technol. 42:1260-1268.

Pagliarini, E., E. Monteleone, and I. Wakeling. 1997. Sensory profile description of mozzarella cheese and its relationship with consumer preference. J. Sens. Stud. 12:285-301.

Pereira, R., L. Matia-Moreno, V. Jones, and H. Singh. 2006. Influence of fat on the perceived texture of set acid milk gels: a sensory perspective. Food Hydrocoll. 20:305-313.

Peyron, M. A., A. Mishellany, and A. Woda. 2004. Particle size distribution of food boluses after mastication of six natural foods. J. Dent. Res. 83:578-582.

Phan, V. A., C. Yvena, G. Lawrence, C. Chabanet, J. M. Reparet, and C. Salles. 2008. In vivo sodium release related to salty perception during eating model cheeses of different textures. Int. Dairy J. 18:956-963.

Piraino, P., T. Zotta, A. Ricciardi, and E. Parente. 2005. Discrimination of commercial Caciocavallo cheeses on the basis of the diversity of lactic microflora and primary proteolysis. Int. Dairy J. $15: 1138-1149$

Rothenbuhler, E. 1972. Die käsereitauglichkeit der milch der HolsteinFriesian im vergleich zu jener der milch des Schweizer Braunviehs und des Simmentaler Fleckviehs. Schweizerische Milchzeitung 98:605-607.

Sato, R. T., A. T. B. Vieira, J. Camisa, P. C. B. Vianna, and C. M. V. B. De Rensis. 2012. Assessment of proteolysis and sensory characteristics of Prato cheese with adjunct culture. Ciênc. Agrár. 33:3143-3152.

Stone, H., and J. L. Sidel. 2004. Sensory Evaluation Practices. 3rd ed. Elsevier Academic Press, London, UK.

Tenenhaus, M., J. Pages, L. Ambroisine, and C. Guinot. 2005. PLS methodology to study relationships between hedonic judgements and product characteristics. Food Qual. Prefer. 16:315-325.

Van Hoorde, K., I. Van Leuven, P. Dirinck, M. Heyndrickx, K. Coudijzer, P. Vandamme, and G. Huys. 2010. Selection, application and monitoring of Lactobacillus paracasei strains as adjunct cultures in the production of Gouda-type cheeses. Int. J. Food Microbiol. 144:226-235.

Virgili, R., G. Parolari, L. Bolzoni, G. Barbieri, A. Mangia, M. Careri, S. Spagnoli, G. Panari, and M. Zannoni. 1994. Sensory-chemical relationships in Parmigiano-Reggiano cheese. Lebenson. Wiss. Technol. 27:491-495.

Wadhwani, R., and D. J. McMahon. 2012. Color of low-fat cheese influences flavor perception and consumer liking. J. Dairy Sci 95:2336-2346.

Ward, C. D. W., C. Stampanoni Koeferli, P. Piccinali Schwegler, D. Schaeppi, and L. E. Plemmons. 1999. European strawberry yogurt market analysis with a case study on acceptance drivers for children in Spain using principal component analysis and partial least squares regression. Food Qual. Prefer. 10:387-400. 